Research Perspective

\title{
Immune checkpoint inhibitors in neuroendocrine tumors: A single institution experience with review of literature
}

\author{
Aman Chauhan ${ }^{1}$, Millicent Horn², Gray Magee ${ }^{2}$, Kurt Hodges ${ }^{3}$, Mark Evers ${ }^{1}$, Susanne \\ Arnold $^{1}$ and Lowell Anthony ${ }^{1}$ \\ ${ }^{1}$ Markey Cancer Center, University of Kentucky, Lexington, KY, USA \\ 2 School of Medicine, University of Kentucky, Lexington, KY, USA \\ ${ }^{3}$ Department of Pathology, University of Kentucky, Lexington, KY, USA
}

Correspondence to: Aman Chauhan, email: amanchauhan@uky.edu

Keywords: immune check point inhibitor; neuroendocrine tumors

Received: October 15,2017 Accepted: December 18, 2017

Published: December 28, 2017

Copyright: Chauhan et al. This is an open-access article distributed under the terms of the Creative Commons Attribution License 3.0 (CC BY 3.0), which permits unrestricted use, distribution, and reproduction in any medium, provided the original author and source are credited.

ABSTRACT

This unique case series and review of literature suggests that immune checkpoint inhibitors may have clinical activity in neuroendocrine tumors.

Objective: Summarize advances of immuno-oncology in neuroendocrine tumors with the help of a case series.

Design: Case series and review of literature.

Intervention or Exposure: The patients were treated with immune checkpoint inhibitors (pembrolizumab or nivolumab).

Main Outcome(s) and Measures(s): Life expectancy, quality of life, disease progression.

Results: Maximum durable response of $\mathbf{1 6}$ months in one of the patients so far. All patients showed improvement in quality of life before disease progression. Two out of four are still on therapy. None of the patients experienced immune checkpoint inhibitor associated side-effects. All patients had failed standard of care therapy prior to the initiation of immune checkpoint inhibitors and were on the verge of hospice.

Conclusions: Immune checkpoint inhibitors have revolutionized cancer management and the last 5 years have seen a rapid expansion in the indications for this class of drug. Neuroendocrine tumors, unfortunately, have been slow to catch on to the immuno-oncology, partly due to difficulties in establishing relevant preclinical neuroendocrine tumors models for immune-oncology studies. In this manuscript, we review the current status of immunotherapy in neuroendocrine tumors.

\section{INTRODUCTION}

Immune checkpoint inhibitors have rapidly advanced in medical oncology. Programmed death-ligand 1 (PD-L1) is a transmembrane protein that binds to the programmed death-1 receptor (PD-1) during immune system modulation. The PD-1 receptor is typically expressed on cytotoxic T-cells and other immune cells while PD-L1 ligand is typically expressed on normal cells [31]. Under normal conditions, cells use the PD-1/PD-L1 interaction as a mechanism of protection against immune recognition via inhibiting the action of T-cells thus downregulating the immune response such that inactive T-cells are exhausted, cease to divide and eventually die by programmed cell death or apoptosis [30]. Studies have shown that numerous types of tumor cells upregulate the expression of PD-L1 as a mechanism to evade the immune response [31]. Activated T-cells recognize the PD-L1 marker on the tumor cell (similar to that of a normal cell) and render the cytotoxic T-cell inactive and thus the tumor cell escapes the immune cycle for elimination and is able to proliferate [31]. Despite a tremendous thrust of anti PD-1 and PDL-1 agents, the realm of neuroendocrine tumors (NETs) seems to be relatively untouched. This 
manuscript summarizes current advances of immunooncology in NETs with the help of a case series (Table 1).

\section{CASE SERIES}

\section{Case 1}

A 43-year-old female was in her usual state of health until about January of 2011 when she developed nausea, vomiting and diarrhea. Diarrhea persisted for a couple of months and she sought medical help in March 2011. Initial conservative management followed by a detailed workup done by a gastroenterologist was negative. Later, in August 2011 the patient presented to ED with complaints of melena. Her CT scan revealed a 9-cm mass in the tail of her pancreas with hepatic metastasis. Liver biopsy confirmed grade 2 neuroendocrine tumor (Ki-67 of $6 \%$ ). The patient was initiated on Sandostatin LAR $30 \mathrm{mg}$ every 30 days. She noticed rapid improvement in her energy level. She subsequently underwent Y90 radio-embolism of hepatic metastatic disease first in the right lobe of the liver followed by the left lobe in the months of September and October 2011. The patient had a stable course until December 2011, she had another episode of GI bleed. In January 2012 she underwent partial pancreatectomy, splenectomy, partial gastrectomy and left hepatic lobectomy. She was started on sunitinib in February 2012, which she had to rapidly discontinue within a month due to severe fatigue. She was started on capecitabine and temozolomide (CAPTEM) in April 2012. The patient tolerated CAPTEM well and started gaining weight. An abdominal MRI from May 2013 showed mild worsening of some of the hepatic lesions, however the rest of the disease was stable. She underwent two more doses of Y-90 radioembolism. She was continued on long acting somatostatin analog and CAPTEM and her subsequent surveillance scan in November 2013 showed stable disease. A follow-up MRI of the abdomen in February 2014 showed mild progression of one of the hepatic lesions. She was taken off CAPTEM and started on everolimus $10 \mathrm{mg}$ daily. We had to reduce the dose of everolimus to $7.5 \mathrm{mg}$ daily due to stomatitis. The patient did exceptionally well on the reduced dose of everolimus and had stable disease until October 2015, at which time she was enrolled into a Phase I clinical trial of fosbretabulin for progressive disease in the liver and retroperitoneum. The patient got the first dose of fosbretabulin in November 2015. She only received three cycles of fosbretabulin before she developed disease progression in the left supraclavicular and left axillary lymph nodes. In February 2016 she was started on off-label pembrolizumab. She had stable disease on pembrolizumab for 16 months before her disease progressed in axilla and breast. Figure 3 shows the current disease burden of patient with help of gallium DOTATATE scan.

\section{Case 2}

A 49-year-old woman was in her usual state of health until 2014 when she presented with complaints of a 6-month history of a non-productive cough, and was found to have pneumonia of the right lung. Scans revealed a right upper lobe lesion. A subsequent bronchoscopy revealed a right upper lobe tumor. On 8/19/2014, the patient underwent an upper lobectomy, and pathology confirmed the diagnosis of stage III a, typical carcinoid (well differentiated NET). Peri-bronchial lymph node (1 out of 7) was also positive for typical carcinoid. In May of 2015, the patient felt a nodule under her skin in her left upper back. A biopsy was consistent with a grade II well differentiated metastatic neuroendocrine tumor. Resection was performed with negative margins, and a postoperative CT was negative for additional metastases. Patient was surveilled with imaging every 3-4 months. An MRI in in fall of 2015 demonstrated progression of the disease in the liver and thorax. She was started on CAPTEM. Unfortunately, patient progressed after five months on CAPTEM. Patient was started on everolimus. She progressed after 3 months and was switched to daily sunitinib. A CT scan in fall of 2016 demonstrated progression of multiple hepatic lesions. She was started on off-label nivolumab (240 mg i.v. every 2 weeks). Patient had stable disease for 6 months on nivolumab before progression and as of now patient has opted hospice. It is to be noted that prior to stating nivolumab patient was losing weight and reported fatigue. Patient had significant

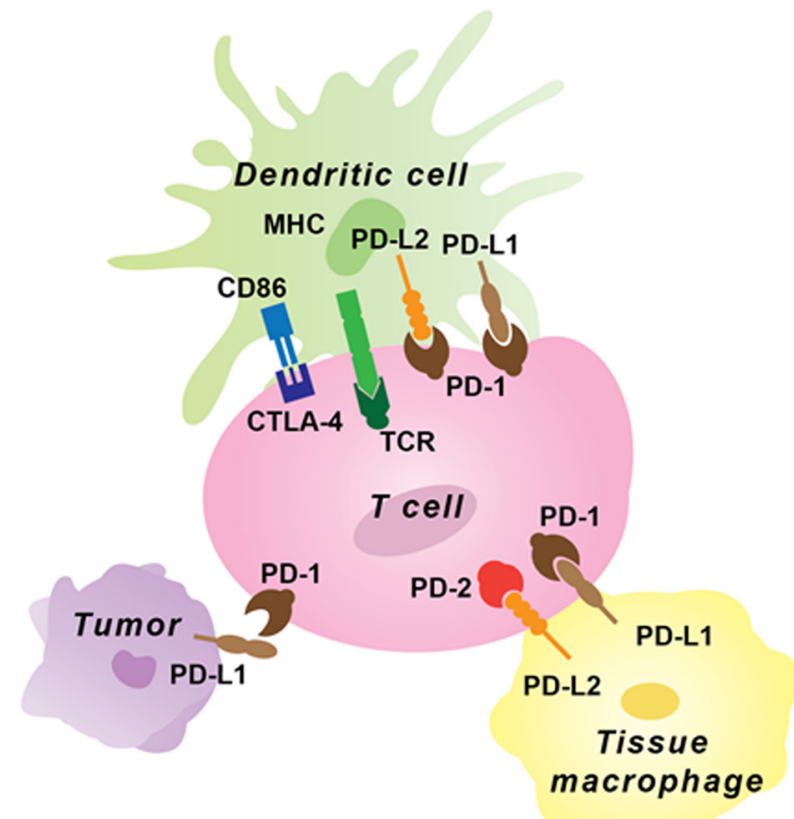

Figure 1: Immune checkpoint inhibitor expression on tumor and immune cells 
improvement in her energy levels and gained 10-15 pounds during first 4-5 months on treatment.

\section{Case 3}

A 71-year-old male underwent a distal pancreatectomy, splenectomy, and a partial gastric resection on 8/12/2012 under the suspicion of the presence of a pancreatic tumor. The resection revealed a grade II pancreatic NET with $5 / 18$ positive nodes. There was evidence of lymphovascular and perineural invasion. In February of 2015, he began treatment on E2211 clinical trial comparing single agent temozolomide to temozolomide + capecitabine, and was randomized to receive temozolomide. After progression, he was switched to CAPTEM in May of 2015. CAPTEM was discontinued in September of 2015 due to progression. He was then switched to long acting somatostatin analog. A CT scan from 10/20/2015 demonstrated interval hepatic metastatic disease progression. He was then started on phase I clinical trial of fosbretabulin in December of 2015. Fosbretabulin is a vascular disrupting agent currently under clinical investigation. Unfortunately, CT scan on 5/23/2016 showed hepatic progression. He was switched to everolimus and progressed after 5 months of therapy. He began off-label nivolumab ( $240 \mathrm{mg}$ i.v. every 2 weeks) in December of 2016. At six months, the patient continues to tolerate the treatment well and shows radiological stable disease.

\section{Case 4}

A 75-year-old woman was initially found to have a left lower lung lobe (LUL) lesion during pre-operative evaluation for right total knee replacement in December 2014. CT demonstrated a $1.4 \mathrm{~cm}$ LUL lesion which was biopsied at outside hospital. Biopsy consisted of 2 FNA which contained neuroendocrine cells positive for synaptophysin, chromogranin, CD56, and CK7 as well as TTF-1. Ki-67 staining was low. There was no evidence of increased mitosis and no necrosis. Morphology and immunohistochemistry were compatible with a welldifferentiated neuroendocrine tumor, although the precise grade (typical vs atypical carcinoid) could not be definitively determined due to limited tissue. Octreotide scan done at outside hospital was noted to be positive with positivity in the left upper lobe and right mid/ lower pulmonary hilum and focal lesion in the liver. She has no evidence of carcinoid syndrome. As it was felt that patient has at least a stage IIIB disease with biopsy proven positive $\mathrm{LN}$ in the contralateral mediastinum. She underwent a LUL video assisted thoracoscopy (VATS) wedge resection. VATS demonstrated a $1.5 \mathrm{~cm}$ moderately to poorly differentiated adenocarcinoma with invasion in the visceral pleura. Surgical margins were negative and tumor was positive for TTF-1. Lymph nodes were negative (pT2 N0 M0, stage IA). She subsequently underwent a bronchoscopy with an ultrasound-guided biopsy and mediastinoscopy. At this procedure, a left lower lobe primary carcinoid tumor of the lung was found, but not resected at that time since it would require a lobectomy. Pathology demonstrated this right lower lobe biopsy to show a well-differentiated neuroendocrine tumor. A level 7 lymph node on the right was also positive for neuroendocrine tumor, well-differentiated. Peritracheal nodes were negative.

In May 2016, she has developed a chronic cough. Subsequent workup demonstrated progressive disease in her chest. Interventional pulmonology and radiation oncology recommended SBRT for obstructive lung lesion. Post radiation, she was started on somatostatin analogs along with everolimus. Gallium DOTATATE PET confirmed progressive metastatic disease in thorax and abdomen. The patient was started on off-label pembrolizumab in June 2017 and her first three monthly surveillance CT scan showed stable disease.

\section{DISCUSSION}

One of the hallmarks of a healthy state is homeostasis between immune activation and degree of inflammatory response. Be it an infectious stimulus or tumors, a well-balanced interplay of immune activation and subsequent shutdown once the aberrant signal protein is eliminated is paramount. An exception to this leads to a pathological state. As scientists began to understand the

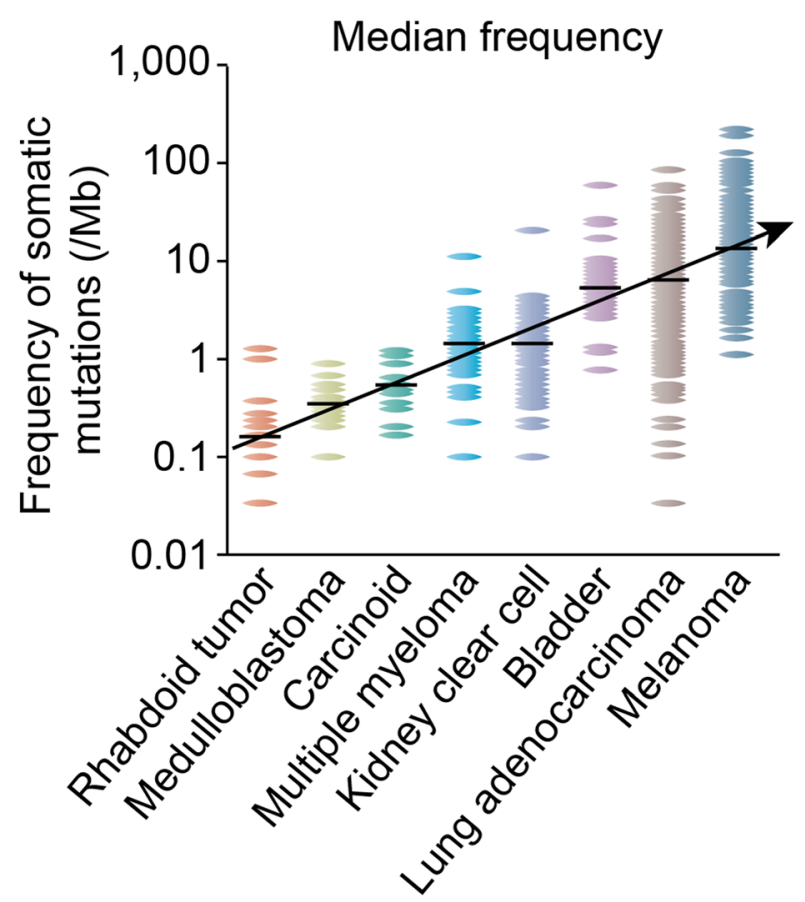

Figure 2: Somatic mutational burden in varying tumor types 
Table 1: Summary of immune checkpoint inhibitor experience in neuroendocrine tumors

\begin{tabular}{|c|c|c|c|c|c|c|}
\hline Patient Age & Diagnosis & Grade & Treatment & Prior Treatments & $\begin{array}{l}\text { Duration } \\
\text { Treatment }\end{array}$ & Outcome \\
\hline 43 & $\begin{array}{lr}\text { Stage } & \text { IV } \\
\text { pNET, } & \text { Non } \\
\text { functional }\end{array}$ & II & Pembrolizumab & $\begin{array}{l}\text { somatostatin } \\
\text { analog, sunitinib, } \\
\text { capecitabine and } \\
\text { temozolamide, } \\
\text { everolimus and } \\
\text { fosbretabulin }\end{array}$ & 16 months & $\begin{array}{l}\text { Progressed after } 16 \text { months } \\
\text { of stable disease; Initially } \\
\text { KPS increased from } 60 \% \text { to } \\
90 \% ; 20 \text { pound weight gain } \\
\text { and enjoyed a good quality } \\
\text { of life for over a year until } \\
\text { progression. }\end{array}$ \\
\hline 49 & $\begin{array}{l}\text { Stage IV NET } \\
\text { of unknown } \\
\text { primary, Non } \\
\text { functional }\end{array}$ & II & Nivolumab & \begin{tabular}{|l|} 
somatostatin \\
analogs, \\
everolimus, \\
capecitabine and \\
temozolomide \\
\end{tabular} & 6 months & $\begin{array}{l}\text { KPS increased from } 70 \% \\
\text { to } 90 \% \text { initially. Progressed } \\
\text { after } 6 \text { months on treatment }\end{array}$ \\
\hline 71 & $\begin{array}{l}\text { Stage IV } \\
\text { pNET, Gastrin } \\
\text { producing }\end{array}$ & I & Nivolumab & $\begin{array}{l}\text { somatostatin } \\
\text { analog, } \\
\text { everolimus, } \\
\text { capecitabine and } \\
\text { temozolomide, } \\
\text { fosbretabulin } \\
\end{array}$ & 6 months & Stable disease per imaging \\
\hline 75 & \begin{tabular}{|l|} 
Stage IV, \\
Bronchial \\
NET, Non \\
functional
\end{tabular} & I & Pembrolizumab & $\begin{array}{l}\text { Somatostatin } \\
\text { analog, } \\
\text { everolimus, XRT }\end{array}$ & 3 months & Stable disease per imaging \\
\hline
\end{tabular}

biology of cancer, it became quite clear that one of the mechanisms by which cancer cells evade our immune response is with the help of immune checkpoints. As noted earlier, most of the known immune checkpoints are in a set of cellular receptors or ligands, which once activated blunt $\mathrm{T}$ cell response against cancer cells. Figure 1 shows the mechanism of action of common immune checkpoint proteins. This led to development of antibodies towards these immune checkpoints with a goal of helping the host immune system to re-recognize these tumor cells as foreign.

Traditionally the mutagenic burden of a tumor type has been thought to predict activity of immune oncology drugs [1]. This hypothesis stems from impressive responses noticed in high mutational burden tumors which may have more neoantigens like lung cancer and melanoma when they are treated with immune checkpoint inhibitors $[2,3]$.

This led to rapid advances in early phase clinical trials in many such tumor types. However, tumors with low mutational burden were left out without any real evidence of lack of PD-1/PD-L1 expression or efficacy. Figure 2 is adapted from a seminal paper from Nature Reviews and shows low mutational burden of well differentiated neuroendocrine tumors (carcinoid) [4].

The notion that low mutational burden predicts poor response to immune checkpoint inhibitors has come into question by some of the leading experts in immune-oncology. This could be due to three factors: Firstly, the data regarding PD-1/PD-L1 expression is expanding even in low mutational burden tumors $[5,24]$. Secondly, there is growing evidence that PD-1/PDL-
1 expression is not static and can change with tumor progression and based on tumor microenvironment [6]. Lastly, PD-1/PD-L1 expression can be augmented with help of immunomodulators. In fact, the newer immune checkpoint inhibitor clinical trials are utilizing concurrent cytotoxic T lymphocyte antigen 4 (CTLA-4) inhibitor, Indoleamine 2,3-dioxygenase inhibitors (IDO), interferon (INF), radiation and cytotoxic chemotherapy to enhance the efficacy of immune checkpoint inhibitors [7-10].

\section{Immuno-oncology in neuroendocrine tumors}

Oberg et al. were among the first researchers to report the potential benefit of interferon (INF) in neuroendocrine tumors. They treated 9 NET patients, including six with carcinoid syndrome, with daily intramuscular INF for three months. All six syndromic patients experienced temporary relief in carcinoid syndrome symptoms and concomitant decline in urinary 5 HIAA levels [11].

Moertel et al. treated 27 of their neuroendocrine tumor patients with interferon. 24 out of 27 patients had carcinoid syndrome. $20 \%$ of the patients had an objective decrease in tumor size. $39 \%$ of functional NET patients experienced reduction in urinary 5 HIAA $(>50 \%)$ levels. These effects were transient for about 4-7 weeks. Moreover, authors recommended against the use of INF due to toxic side-effects which included fever, fatigue, and weight loss [12].

In a subsequent prospective randomized clinical trial of octreotide $(n=35)$ versus octreotide with INF $(n=33)$ for metastatic midgut carcinoid tumor patients, a superior 
Table 2: Current status of Immune checkpoint inhibitor in prospective clinical trials for neuroendocrine tumors

\begin{tabular}{|c|c|c|c|c|c|}
\hline & NCT ID & Disease cohort & $\begin{array}{l}\text { Investigational } \\
\text { Agent }\end{array}$ & Phase & $\begin{array}{l}\text { Current } \\
\text { Status }\end{array}$ \\
\hline $\begin{array}{l}\text { Phase 2, Open-label Study of } \\
\text { pembrolizumab monotherapy } \\
\text { in Patients with Metastatic High } \\
\text { Grade Neuroendocrine Tumors }\end{array}$ & 02939651 & $\begin{array}{l}\text { Stage IV, } \\
\text { neuroendocrine tumor }\end{array}$ & $\begin{array}{l}\text { Pembrolizumab } \\
200 \mathrm{mg} \text { every } 3 \text { weeks }\end{array}$ & 2 & Recruiting \\
\hline $\begin{array}{l}\text { Study of pembrolizumab } \\
\text { With lanreotide Depot for } \\
\text { Gastroenteropancreatic } \\
\text { Neuroendocrine } \\
\text { (PLANET) }\end{array}$ & 03043664 & $\begin{array}{l}\text { Stage IV well or } \\
\text { moderately differentiated } \\
\text { gastroenteropancreatic } \\
\text { neuroendocrine tumors } \\
\text { (GEP-NETs) }\end{array}$ & \begin{tabular}{|l|} 
Pembrolizumab \\
$200 \mathrm{mg}$ IV every 3 \\
weeks and Lanreotide \\
depot 90mg SQ every \\
3 weeks
\end{tabular} & $1 / 2$ & Recruiting \\
\hline $\begin{array}{l}\text { Study of Efficacy and Safety } \\
\text { of PDR001 in Patients with } \\
\text { Advanced or Metastatic, Well- } \\
\text { differentiated, Non-functional } \\
\text { Neuroendocrine Tumors of } \\
\text { Pancreatic, Gastrointestinal } \\
\text { (GI), or Thoracic Origin } \\
\text { or Poorly-differentiated } \\
\text { Gastroenteropancreatic } \\
\text { Neuroendocrine Carcinoma } \\
\text { (GEP-NEC) }\end{array}$ & 02955069 & $\begin{array}{l}\text { Stage IV, Well differentiated } \\
\text { non-functional NET of GI, } \\
\text { Pancreas and Lungs } \\
\text { Poorly differentiated } \\
\text { gastroenteropancreatic } \\
\text { neuroendocrine carcinoma }\end{array}$ & $\begin{array}{l}\text { PDR001 dose is } 400 \\
\text { mg infusion every } 4 \\
\text { weeks } \\
\text { PDR001 is a high- } \\
\text { affinity, ligand- } \\
\text { blocking, humanized } \\
\text { IgG4 antibody } \\
\text { directed against } \\
\text { Programmed Death-1 } \\
\text { (PD-1) receptor that } \\
\text { blocks the binding of } \\
\text { PD-L1 and PD-L2. }\end{array}$ & 2 & Recruiting \\
\hline $\begin{array}{l}\text { Pharmaco-immunological } \\
\text { Study of Interferon-alpha and } \\
\text { Metronomic Cyclophosphamide } \\
\text { Association in Neuroendocrine } \\
\text { Tumors (EPICentro) }\end{array}$ & 02838342 & $\begin{array}{l}\text { Grade } 1 \text { or } 2 \text { metastatic } \\
\text { neuroendocrine tumor }\end{array}$ & $\begin{array}{l}\text { Metronomic } \\
\text { cyclophosphamide } \\
\text { Interferon-alpha }\end{array}$ & 2 & Recruiting \\
\hline $\begin{array}{l}\text { Study of JS001 in Patients with } \\
\text { Advanced Neuroendocrine } \\
\text { Tumors }\end{array}$ & 03167853 & $\begin{array}{l}\text { Stage IV, Grade } 2 \text { or } \\
3, \quad \text { well-differentiated } \\
\text { neuroendocrine tumors and } \\
\text { poorly-differentiated }\end{array}$ & $\begin{array}{l}\text { JS } 001 \text { humanized } \\
\text { anti-PD-1 monoclonal } \\
\text { antibody }\end{array}$ & 1 & Recruiting \\
\hline $\begin{array}{l}\text { Durvalumab (MEDI4736) plus } \\
\text { tremelimumab for Advanced } \\
\text { Neuroendocrine Neoplasms of } \\
\text { Gastroenteropancreatic or Lung } \\
\text { Origin (DUNE) }\end{array}$ & 03095274 & $\begin{array}{l}\text { G1-2 GI, Pancreatic and } \\
\text { Bronchial NET and G3 non- } \\
\text { thoracic neuroendocrine } \\
\text { carcinoma. }\end{array}$ & $\begin{array}{l}\text { Durvalumab, } \quad 1500 \\
\text { mg Q4W } \\
\text { Tremelimumab } 75 \mathrm{mg} \\
\text { Q4W }\end{array}$ & 2 & Recruiting \\
\hline
\end{tabular}

progression free survival was evident for the combination arm; however, no significant difference was seen in overall survival [13].

Another randomized clinical trial done at around same time compared the efficacy of lanreotide $(n=25)$ to INF-alpha $(n=27)$ and the combination of lanreotide and INF-alpha $(n=28)$ in metastatic gastroenteropancreatic neuroendocrine tumor patients. The study concluded that the experimental agents had comparable anti-neoplastic activity in NETs but response rates were very poor. Only 19 patients out of 80 showed stable disease at 12 months [14]. Arnold et al. prospectively studied interferon plus octreotide $(n=54)$ versus octreotide alone $(n=51)$ in 105 gastroenteropancreatic tumor patients. The median survival was 54 months in the combination arm vs 32 months in the octreotide only arm. The study could not establish superiority of the combination arm due to lack of statistical significance [15].

Based on the above mentioned weak evidence, marginal benefit and lack of therapeutic options, NCCN recommends (category 3) INF as one of the potential treatment choices for metastatic gastrointestinal and thoracic NET [16]. This recommendation fortunately has fallen off favor in general community practice. 


\section{Modern immuno-oncology and NETs}

Ipilumumab, a monoclonal antibody against cytotoxic T lymphocyte antigen 4 (CTLA4), was approved in March 2011 and was the first immune checkpoint inhibitor to show an overall survival advantage in metastatic melanoma [17]. Theoretically, the efficacy of immune checkpoint inhibitors should be affected by the presence of tumor infiltrating lymphocytes (TILs). Increased TILs should in principle enhance the activity of anti-CTLA4 drugs. Although we have no direct prospective data on the efficacy of CTLA-4 agents in NETs, there is indirect data to suggest that immune checkpoint inhibitors might have activity in NETs.

Ryschich et al. were the first to demonstrate the presence of $\mathrm{CD} 3+\mathrm{T}$ cells in pancreatic neuroendocrine tumors (PNET) [18]. Later, a series published by Kat et al. from Memorial Sloan Kettering analyzed post-operative tumor specimens of 87 patients with primary PNET for TILs. They found a statistically significant difference in survival of intermediate grade (Ki 67 2-20\%) PNET based on TIL density. Patients with dense T cell infiltration in tumor tissue had a median recurrence-free survival of 128 months as compared to 62 months in the subset with low TILs $(p=0.05)[19]$.

Drug development for high grade NETs usually follows trends seen in small cell lung cancer, a pulmonary high grade NET. Reck et al. were among the first to study ipilumumab in extensive stage small cell lung cancer (SCLC). Phased ipilumumab with carboplatin/paclitaxel vs carboplatin/paclitaxel alone showed a statistically significant difference in irPFS (HR (hazard ratio) = $0.64 ; \mathrm{p}=0.03$ ). Although the improvement in irPFS did not translate into overall survival it was nevertheless indicative of drug efficacy in this tumor type [20].

Checkmate 032 evaluated nivolumab vs nivolumab plus ipilumumab in 128 SCLC patients who had progressed on prior platinum-based regimens. The overall response rate was $18 \%$ vs $32.6 \%$ for the combination arm [21]. The therapy showed significant antitumor activity, while maintaining durable responses and a manageable toxicity profile in patients with progressed SCLC. Keynote 028 evaluated pembrolizumab in PD-L1 positive progressive SCLC patients. Out of 24 treated patients one patient had complete response and 8 had partial response. ORR was $37.5 \%$ [28]. Whether these agents will prove to be effective in non-pulmonary high-grade NETs is yet to be seen.

A recent retrospective study from Korea evaluated PD-L1 expression in metastatic gastroenteropancreatic (GEPNET) patients through immunohistochemical analysis. 7 out of 32 patient tumor tissues $(21.9 \%)$ were found to be positive for PD-L1. Grade 3 GEPNETs were especially correlated with PD-L1 expression ( $p=0.008)$ [22]. Additionally, the researchers found that patients expressing PD-L1 had a shorter progression-free survival time and a shorter overall survival. The presence of PDL1 was also linked to a higher tumor grade (grade 3) in metastatic GEPNETs. The presence of PD-L1 in these patients could act as a biomarker to predict survival.

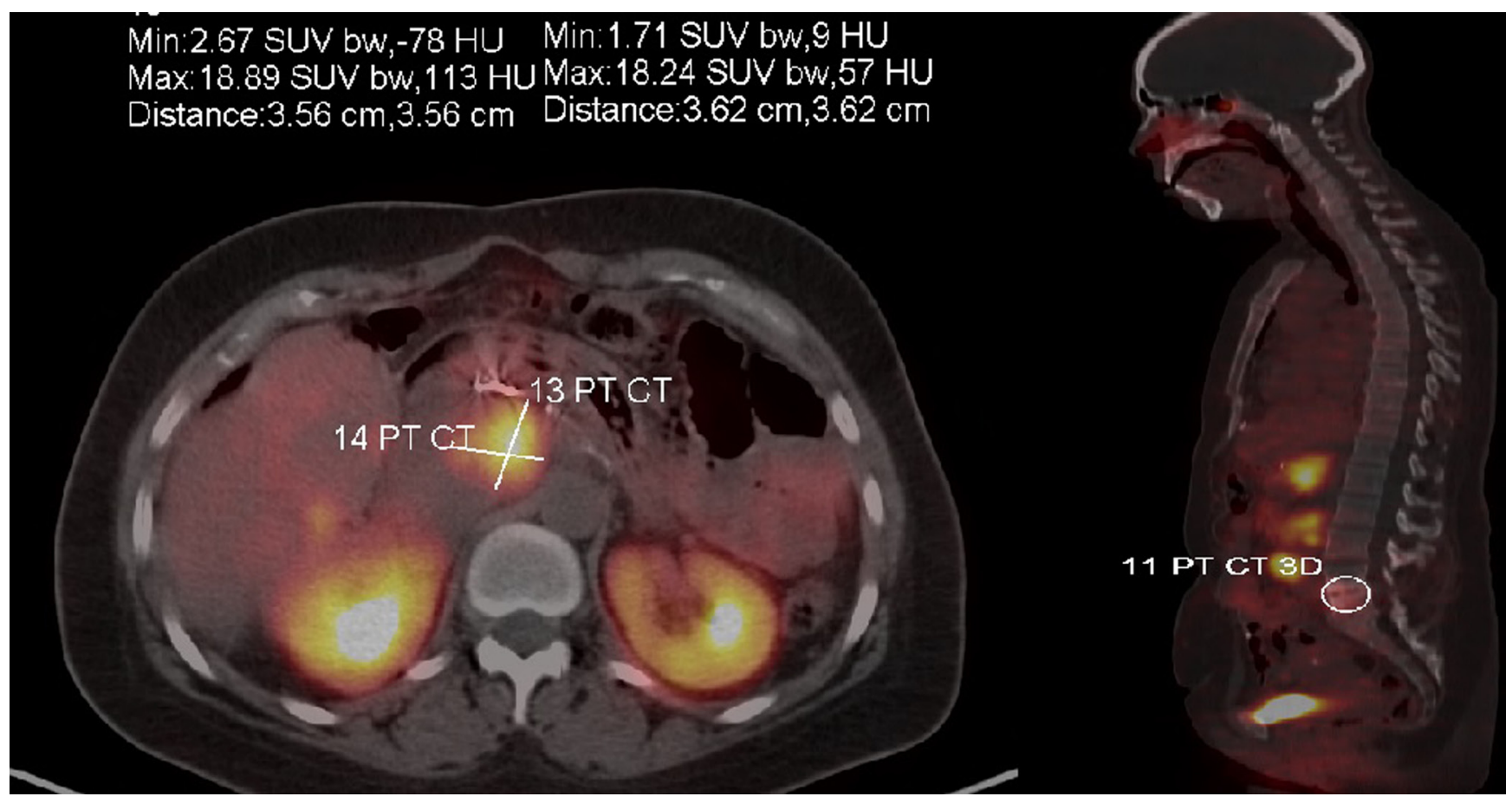

Figure 3: Gallium DOTATATE scan sowing disease burden at the time of progression on immune checkpoint inhibitor therapy (case 1) 
Ultimately, inhibition of PD-L1 could serve as a novel therapy for patients with metastatic GEPNETs.

Leng et al. reported PD-L1 expression in 13 out of 45 GI neuroendocrine tumor patients. PD-L1 positive tumors were all poorly differentiated NETs [23]. Additionally, there was a significant correlation between the presence of PD-L1 expression and tumor grade. Cives et al. found 22 of their 32 GI NETs positive for PD-L1 expression. Moreover, PD-L1 expression was related to worse outcomes as 5-year overall survival was $32 \%$ in PD-L1 positive patients versus $90 \%$ in PD-L1 negative patients [24].

Tsuruoka et al recently published their results on PD-L1 expression in thoracic neuroendocrine tumors. The authors conducted immunohistochemistry on tissue microarray with E1L3N, a PD-L1 antibody clone. The study samples were examined by two blinded independent investigators. A score of 1 or more was considered to be positive for PD-L1 expression. Out of 227 patients, 46 were typical carcinoids (TC), 6 were atypical carcinoids (AC), 106 were large cell neuroendocrine carcinoma (LCNEC) and 69 were small cell lung carcinoma (SCLC). None of the TC and AC were found to be positive for PDL1 expression. 5.8\% $(n=4)$ SCLC and 10.4\% $(n=11)$ LCNEC patients were found PD-L1 positive [27]. It seems the PD-L1 expression is variable among neuroendocrine tumors and high grade neuroendocrine tumors might have higher odds of being PD-L1 positive especially gastroenteropancreatic origin.

There have been two recent reports evaluating prognostic implication of PD-L1 and PD-1 expression in NETs. Fan et al. investigated 80 pulmonary neuroendocrine patients. 51.3\% (41) patients had positive PD-1 expression in tumor infiltrating lymphocytes. A multivariate analysis of their study cohort revealed that both PD-1 and PD-L1 expression were independent survival prognostic factors [29]. Kim et al studied prognostic implication of PDL1 expression in GEPNETs. 24 GEPNET patients were evaluated for PD-L1 expression and authors found that median overall survival in PD-L1 positive patients was 16 months as compared to 24.8 months in PD-L1 negative patients [30].

Table 2 summarizes the ongoing clinical trials evaluating clinical activity of immune checkpoint inhibitors in neuroendocrine tumors.

\section{CONCLUSION}

Specific clinical trials looking at just GEPNETs and immune checkpoint inhibitors are limited (Table 2) and although the results of these trials are still a few years away, it's a step in right direction. Neuroendocrine tumors are an area of unmet medical need and despite increasing incidence and prevalence, the treatment options for progressive disease are limited. NET incidence has been rising over the past four decades. We recently presented our 18-year Kentucky Cancer Registry database review at a national neuroendocrine symposium and found multifold increase in incidence of NETs from 3.76/100,000 to $10.7 / 100,000$ population [25]. This is consistent with the surge in incidence seen at the national level per SEER database [26]. As most decisions in drug development are affected by pharmacoeconomics, continued efforts from the medical fraternity exploring the role of immune checkpoint inhibitors in NETs might turn the tide.

Our patients certainly benefited from a trial of immune checkpoint inhibitors without any adverse side effects. Overall, we were able to provide some degree of disease stabilization and improved performance status. It is to be noted that all our study patients had otherwise exhausted all standard of care treatment options and were on the verge of hospice. Our single center experience shows encouraging results. We eagerly await results of prospective clinical trials.

\section{ACKNOWLEDGMENTS}

The authors thank Donna Gilbreath in Markey Cancer Center's Research Communications Office for assistance with manuscript and figure preparation.

\section{CONFLICTS OF INTEREST}

None of the authors disclose any relevant conflict of interests.

\section{REFERENCES}

1. Madore J, Strbenac D, Vilain R, Menzies AM, Yang JY, Thompson JF, Long GV, Mann GJ, Scolyer RA, Wilmott JS. PD-L1 Negative Status is Associated with Lower Mutation Burden, Differential Expression of ImmuneRelated Genes, and Worse Survival in Stage III Melanoma. Clin Cancer Res. 2016; 22:3915-23.

https://doi.org/10.1158/1078-0432.CCR-15-1714

2. Reck M, Rodríguez-Abreu D, Robinson AG, Hui R, Csőszi T, Fülöp A, Gottfried M, Peled N, Tafreshi A, Cuffe S, O'Brien M, Rao S, Hotta K, et al, and KEYNOTE-024 Investigators. Pembrolizumab versus Chemotherapy for PD-L1-Positive Non-Small-Cell Lung Cancer. N Engl J Med. 2016; 375:1823-33.

https://doi.org/10.1056/NEJMoa1606774

3. Robert C, Long GV, Brady B, Dutriaux C, Maio M, Mortier L, Hassel JC, Rutkowski P, McNeil C, Kalinka-Warzocha E, Savage KJ, Hernberg MM, Lebbé C, et al. Nivolumab in previously untreated melanoma without BRAF mutation. $\mathrm{N}$ Engl J Med. 2015; 372:320-30.

https://doi.org/10.1056/NEJMoa1412082

4. Lawrence MS, Stojanov P, Polak P, Kryukov GV, Cibulskis K, Sivachenko A, Carter SL, Stewart C, Mermel CH, Roberts SA, Kiezun A, Hammerman PS, McKenna A, et al. 
Mutational heterogeneity in cancer and the search for new cancer-associated genes. Nature. 2013; 499:214-18.

https://doi.org/10.1038/nature12213

5. Kim C, Kim EK, Jung H, Chon HJ, Han JW, Shin KH, Hu H, Kim KS, Choi YD, Kim S, Lee YH, Suh JS, Ahn JB, et al. Clinical pattern and implication of PD-L1 expression in soft-tissue sarcoma. BMC Cancer. 2016; 16:434.

https://doi.org/10.1186/s12885-016-2451-6

6. Rech AJ, Vonderheide RH. Dynamic interplay of oncogenes and $\mathrm{T}$ cells induces PD-L1 in the tumor microenvironment. Cancer Discov. 2013; 3:1330-32. https://doi.org/10.1158/2159-8290.CD-13-0775

7. Deng L, Liang H, Burnette B, Beckett M, Darga T, Weichselbaum RR, Fu YX. Irradiation and anti-PD-L1 treatment synergistically promote antitumor immunity in mice. J Clin Invest. 2014; 124:687-95.

https://doi.org/10.1172/JCI67313

8. Terawaki S, Chikuma S, Shibayama S, Hayashi T, Yoshida T, Okazaki T, Honjo T. IFN- $\alpha$ directly promotes programmed cell death-1 transcription and limits the duration of T cell-mediated immunity. J Immunol. 2011; 186:2772-79. https://doi.org/10.4049/jimmunol.1003208

9. Zeng J, See AP, Phallen J, Jackson CM, Belcaid Z, Ruzevick J, Durham N, Meyer C, Harris TJ, Albesiano E, Pradilla G, Ford E, Wong J, et al. Anti-PD-1 blockade and stereotactic radiation produce long-term survival in mice with intracranial gliomas. Int J Radiat Oncol Biol Phys. 2013; 86:343-49.

https://doi.org/10.1016/j.ijrobp.2012.12.025

10. Munn DH. Blocking IDO activity to enhance anti-tumor immunity. Front Biosci (Elite Ed). 2012; 4:734-45.

https://doi.org/10.2741/e414

11. Oberg K, Funa K, Alm G. Effects of leukocyte interferon on clinical symptoms and hormone levels in patients with mid-gut carcinoid tumors and carcinoid syndrome. N Engl J Med. 1983; 309:129-33.

https://doi.org/10.1056/NEJM198307213090301

12. Moertel CG, Rubin J, Kvols LK. Therapy of metastatic carcinoid tumor and the malignant carcinoid syndrome with recombinant leukocyte A interferon. J Clin Oncol. 1989; 7:865-68. https://doi.org/10.1200/JCO.1989.7.7.865

13. Kölby L, Persson G, Franzén S, Ahrén B. Randomized clinical trial of the effect of interferon alpha on survival in patients with disseminated midgut carcinoid tumours. Br J Surg. 2003; 90:687-93. https://doi.org/10.1002/bjs.4149

14. Faiss S, Pape UF, Böhmig M, Dörffel Y, Mansmann U, Golder W, Riecken EO, Wiedenmann B, and International Lanreotide and Interferon Alfa Study Group. Prospective, randomized, multicenter trial on the antiproliferative effect of lanreotide, interferon alfa, and their combination for therapy of metastatic neuroendocrine gastroenteropancreatic tumors - the International Lanreotide and Interferon Alfa Study Group. J Clin Oncol. 2003; 21:2689-96.
https://doi.org/10.1200/JCO.2003.12.142

15. Arnold R, Rinke A, Klose KJ, Müller HH, Wied M, Zamzow K, Schmidt C, Schade-Brittinger C, Barth P, Moll R, Koller M, Unterhalt M, Hiddemann W, et al. Octreotide versus octreotide plus interferon-alpha in endocrine gastroenteropancreatic tumors: a randomized trial. Clin Gastroenterol Hepatol. 2005; 3:761-71.

https://doi.org/10.1016/S1542-3565(05)00481-7

16. Kulke M, Shah M, Benson AB, Berlin J, Emerson L, Engstrom P. National Comprehensive Cancer Network. Neuroendocrine Tumors of the GI, Lung and Thymus (CarcinoidTumors).2016

http://www.iqandacme.com/assets/pdf/NCCN\%20

Guidelines_Neuroendocrine\%20Tumors.pdf

17. Robert C, Thomas L, Bondarenko I, O'Day S, Weber J, Garbe C, Lebbe C, Baurain JF, Testori A, Grob JJ, Davidson N, Richards J, Maio M, et al. Ipilimumab plus dacarbazine for previously untreated metastatic melanoma. N Engl J Med. 2011; 364:2517-26.

https://doi.org/10.1056/NEJMoa1104621

18. Ryschich E, Autschbach F, Eisold S, Klar E, Buchler MW, Schmidt J. Expression of HLA class I/II antigens and T cell immune response in human neuroendocrine tumors of the pancreas. Tissue Antigens. 2003; 62:48-54.

https://doi.org/10.1034/j.1399-0039.2003.00075.x

19. Katz SC, Donkor C, Glasgow K, Pillarisetty VG, Gönen M, Espat NJ, Klimstra DS, D'Angelica MI, Allen PJ, Jarnagin W, Dematteo RP, Brennan MF, Tang LH. T cell infiltrate and outcome following resection of intermediate-grade primary neuroendocrine tumours and liver metastases. HPB. 2010; 12:674-83.

https://doi.org/10.1111/j.1477-2574.2010.00231.x

20. Reck M, Bondarenko I, Luft A, Serwatowski P, Barlesi F, Chacko R, Sebastian M, Lu H, Cuillerot JM, Lynch TJ. Ipilimumab in combination with paclitaxel and carboplatin as first-line therapy in extensive-disease-smallcell lung cancer: results from a randomized, double-blind, multicenter phase 2 trial. Ann Oncol. 2013; 24:75-83.

https://doi.org/10.1093/annonc/mds213

21. Antonia SJ, López-Martin JA, Bendell J, Ott PA, Taylor M, Eder JP, Jäger D, Pietanza MC, Le DT, de Braud F, Morse MA, Ascierto PA, Horn L, et al. Phase I/II study of nivolumab with or without ipilimumab for treatment of recurrent small cell lung cancer (SCLC): CA209-032. Lancet Oncol. 2016; 17:883-95.

https://doi.org/10.1016/S1470-2045(16)30098-5

22. Kim ST, Ha SY, Lee S, Ahn S, Lee J, Park SH, Park JO, Lim HY, Kang WK, Kim KM, Park YS. The Impact of PDL1 Expression in Patients with Metastatic GEP-NETs. J Cancer. 2016; 7:484-89. https://doi.org/10.7150/jca.13711

23. Li Z, Leng J, Wang H, Li S, Lu M, Zhou L, Huang X, Jia L, Kang Q, Li J, Shen L, Lin D. PDL1 expression is associated with grade of neuroendocrine tumors. 13th Annual 
ENETS Conference for the Diagnosis and Treatment of Neuroendocrine Tumor Disease; 2016; Barcelona, Spain.

24. Cives M, Strosberg J, Coppola D. PD1 and PDL1 expression in midgut neuroendocrine tumors. 13th Annual ENETS Conference for the Diagnosis and Treatment of Neuroendocrine Tumor Disease; 2016; Barcelona, Spain.

25. Chauhan A, Ray N, Huang B, Durbin E, Anthony L, Tucker T. Neuroendocrine tumor incidence over 18 years: Kentucky Cancer Registry vs SEER. 2016 NANETS Symposium; 2016; Jackson, WY, USA.

26. Yao JC, Hassan M, Phan A, Dagohoy C, Leary C, Mares JE, Abdalla EK, Fleming JB, Vauthey JN, Rashid A, Evans DB. One hundred years after "carcinoid": epidemiology of and prognostic factors for neuroendocrine tumors in 35,825 cases in the United States. J Clin Oncol. 2008; 26:3063-72. https://doi.org/10.1200/JCO.2007.15.4377

27. Tsuruoka K, Horinouchi H, Goto Y, Kanda S, Fujiwara Y, Nokihara H, Yamamoto N, Asakura K, Nakagawa K, Sakurai H, Watanabe SI, Tsuta K, Ohe Y. PD-L1 expression in neuroendocrine tumors of the lung. Lung Cancer. 2017; 108:115-20. https://doi.org/10.1016/j.lungcan.2017.03.006
28. Ott PA, Elez E, Hiret S, Kim DW, Morosky A, Saraf S, Piperdi B, Mehnert JM. Pembrolizumab in Patients with Extensive-Stage Small Cell Lung Cancer: Updated Survival Results from KEYNOTE-028. J Clin Oncol. 2017; 35:382329. https://doi.org/10.1200/JCO.2017.72.5069

29. Fan Y, Ma K, Wang C, Ning J, Hu Y, Dong D, Dong X, Geng Q, Li E, Wu Y. Prognostic value of PD-L1 and PD-1 expression in pulmonary neuroendocrine tumors. Onco Targets Ther. 2016; 9:6075-82.

https://doi.org/10.2147/OTT.S115054

30. Disis ML. Mechanism of action of immunotherapy. Semin Oncol. 2014; 41:S3-13.

https://doi.org/10.1053/j.seminoncol.2014.09.004

31. Sweis RF, Luke JJ. Mechanistic and pharmacologic insights on immune checkpoint inhibitors. Pharmacol Res. 2017; 120:1-9. https://doi.org/10.1016/j.phrs.2017.03.012 